\title{
Pedagogy: Instructivism to Socio-Constructivism through Virtual Reality
}

\author{
Moses O. Onyesolu ${ }^{1}$, Victor C. Nwasor ${ }^{2}$, Obiajulu E. Ositanwosu ${ }^{3}$ and Obinna N. Iwegbuna ${ }^{4}$ \\ ${ }^{1,3,4}$ Department of Computer Science \\ ${ }^{2}$ Department of Educational Foundations \\ Nnamdi Azikiwe University, Awka Anambra State, Nigeria
}

\begin{abstract}
-learning theories evolved with time, beginning with instructivism, constructivism, to social constructivism. These theories no doubt were applied in education and they had their effects on learners. Technology advanced, created a paradigm shift by creating new ways of teaching and learning as found in virtual reality (VR). VR provided creative ways in which students learn, provides opportunity to achieve learning goals by presenting artificial environments. We developed and simulated a virtual reality system on a desktop by deploying Visual Basic.NET, Java and Macromedia Flash. This simulated environment enhanced students' understanding by providing a degree of reality unattainable in a traditional two-dimensional interface, creating a sensory-rich interactive learning environment.
\end{abstract}

Keywords-learning theory; virtual reality; simulated environment; education; pedagogy

\section{INTRODUCTION}

Education in its general sense is a form of learning in which knowledge, skills and habits of a group of people are transferred through teaching, training, and research or auto didacticism [1]. It has been a means of transmitting one's culture from one generation to another. It is the process of bringing about a relatively permanent change in human behavior [2]. In its narrow, technical sense, education is the formal process by which society deliberately transmits its accumulated knowledge, skills, customs and values from one generation to another, e.g., instruction in schools [3]. Being the oldest industry, it is the main instrument used by society to preserve, maintain and upgrade its social equilibrium. A society's future depends largely on the quality of its citizen's education. Educators around the world today have leaning towards different theories of learning and as such some believe that these theories do not have to dictate how they teach or have to influence the way learner learn [4].

Instructivism, constructivism and socio-constructivism are the notable theories and practices on pedagogy today which still hinge on the works of earlier philosophy on teaching and learning, though earlier theorists in education are evenly divided on varying conception on teaching and learning. Technology has had effect on these theories as a result of man's ingenuity. In the fields of education, technology has created a paradigm shift, which has created new ways of teaching, and learning. Technology through intelligence has provided creative ways in which students learn and has provided opportunities to guide classroom instruction to meet all learners [5] and [6]. Virtual Reality (VR), a technology of the $21^{\text {st }}$ century has had impact on learning and changed the thinking of educators [7]. The remainder of the paper is presented as follows: Section 2 provided the background of some learning theories and Virtual Reality. Section 3 looked into some VR learning environments. Section 4 presented the materials and methods employed in the study. Section 5 presented the results and discussions while section 6 concluded the paper.

\section{BACKGROUND INFORMATION}

\section{A. Instructivism}

The Instructivist approach to learning is otherwise referred to as objectivist or institutionalist. Instructivism places emphasis on the passage of information and knowledge encapsulating activities and other learning events for learning to take place thereby resulting in a change of behaviour, attitude, belief etc. Instructivist helps learner to reproduce a series of facts, knowledge, attitude, belief and behavior [4]. The theory of instructivism maintains that knowledge should be transferred directly into the mind of the learner from the instructor. This knowledge is expected to be wholly accepted and not questioned by the learner or even analyzed by him [8]. This learning theory asserts that while the teachers are primary learning agents, students are passive information absorbers. It is thus a process of cognitive dumping in which all the learner has to do is to memorize unprocessed information. Instructivism is a very old learning approach. The lecture method of teaching is found under this domain, and this is where according to [8], 70\% - 90\% of university professors fall under. Instructivism/Instructionism involves making associations with stimuli, emphasizes drill and practices and memorization. This conditional learning does not give room for self-discovery. Instructivism, a traditional model of teaching and learning is nor learner-centered.

\section{B. Constructivism}

Although constructivism has been argued and often referred to as a new orthodoxy, fad, movement, religion with different sects and purely ideological theory [9] and [10], it cannot be over-emphasized that a learner enters his learning situation with pre-conceived notions or ideas about many phenomena [11]. The constructivist theory is rooted in the idea that the learner actively constructs his knowledge, not that it is passively acquired from without [11]. Learning is something the learner does, not that it is imposed on the learner. The 
learner uses individual ideas as tools to understand many phenomena presented to him by the teacher.

Piaget contributed to the constructivist theory in Educational Psychology by delineating stages of intellectual development [12]. Influenced by the Piagetian thought afloat in educational circles, Driver and Easly [13] discovered the concrete ideas brought in as "Entry Behaviour" by children to the learning environment. This helped to change the research agenda in science education to encompass constructivist patterns in which learners construct their own knowledge as pot-pouri of ideas (self-generated from teachers). Educational constructivism has long been associated with advanced pedagogy on the basis that it champions a learner-centered approach to teaching, advocates learning in meaningful contexts, and promotes problem-based activities where learners construct their knowledge through interaction with their peers [14].

In constructivism, the teacher is seen as a facilitator/guide instead of being a director, in that learning allows for creative intercourse with the teacher, instead of teaching based on outcomes [15]. Discovery is seen to direct the learner to construct his own knowledge. Knowles, Holton and Swanson [16] gave impetus to this position by adding that constructivism emphasizes knowledge as being bound by context, giving room for individuals to make meaning out of their respective learning experiences.

\section{Social Constructivism}

With obvious influences from Piaget's constructivist idea, social constructivism emphasizes the importance of culture and context in giving meaning to what happens in society and constructing knowledge from this understanding [17]. The social constructivist outgrowth of thought in educational psychology is associated chiefly with Lev Vygotsky, Jerome Bruner, and Albert Bandura [11].

The basic assumptions that underlie social constructivism are Reality, Knowledge, Learning and Intersubjectivity of Social Meanings. Social constructivists opine that human activity constructs reality. Reality is thus invented by society together [18]. Knowledge is also believed to be a product of human input and is constructed socio-culturally [19]; hence interactions with one another and their physical and social environments aids individuals in creating meanings.

Learning is seen as a social activity, not a passive behavioural development shaped by external, unempatheic forces. McMahon [17] has it that learning takes place as individuals involves in social activities. Describing intersubjectivity, Rogolf [20] refers to it as a shared understanding among individuals who interact based on common interest and assumptions that gives room for their communication. Social meanings are thus created based on intersubjectivity among individuals and social negotiation within communicating groups of individuals [21]. Vygotsky suggests that intersubjectivity helps individuals to extend their understanding of information to other group members. Such learning is collaborative in nature. In social constructivism, both the learning and social contexts are crucial to understanding.

\section{Virtual Reality(VR)}

VR is used to describe a range of computer-based systems in which a user can explore hardware and software generated 'microworld' that bears some resemblance to reality [22]. Virtual reality (VR) is a class of computer-controlled multisensory communication technologies that allow more intuitive interactions with data and involve human senses in new ways. VR is basically a way of simulating or replicating an environment and giving the user a sense of being there, taking control, and personally interacting with that environment with his/her own body [23] and [24]. VR is a technology which allows a user to interact with a computersimulated environment, be it a real or imagined one [25]. VR is potentially a tool for experiential learning. The virtual world is interactive; it responds to the user's actions. Virtual reality evokes a feeling of immersion, a perceptual and psychological sense of being in the digital environment presented to the senses. The sense of presence or immersion is a critical feature distinguishing virtual reality from other types of computer applications. Virtual Reality is an artificial environment created and maintained by a computer and that is at least partly shaped and determined by the user. A VR system allows the user to depart the real world and step into a world whose sensory inputs (sights, sounds, smells, etc.) are provided not by natural objects but by computer-created means. The objects and processes in the virtual world can then be manipulated to a large extent by the user. The use of VR techniques in the development of educational applications brings new perspectives to the teaching of subjects. An understanding of the technology and techniques is imperative.

VR is classified into three major types: (a) Non-Immersive VR Systems, (b) Semi-Immersive VR Systems and (c) Immersive (Fully Immersive) VR systems [23]. NonImmersive VR Systems are the least implementation of VR techniques. It involves implementing VR on a desktop computer. This class is also known as Window on World (WoW) [26]. Using the desktop system, the virtual environment is viewed through a portal or window by utilizing a standard high resolution monitor. Interaction with the virtual environment can occur by conventional means such as keyboard, mouse or trackball. Semi-Immersive VR Systems comprise of a relatively high performance graphics computing system which can be coupled with either a large screen monitor; a large screen projection system or multiple television projection system. Using a wide field of view, these systems increase the feeling of immersion or presence experienced by the user and stereographic imaging can be achieved using some type of shutter glasses. Immersive (Fully Immersive) VR Systems are most direct experience of virtual environments.

Here the user either wears an head mounted display (HMD) or uses some form of head-coupled display such as a Binocular Omni-Orientation Monitor (BOOM) to view the virtual environment, in addition to some tracking devices and haptic devices. An HMD or BOOM uses small monitors placed in front of each eye which provide stereo, binocular or monocular images. More successful and popular is the Cave Automatic Virtual Environment (CAVE), In CAVE environments, the illusion of immersion is created by 
projecting stereo images on the walls and floor of a room-size cube. Participants wearing lightweight stereo glasses enter and walk freely within the CAVE room, while a head-tracking computer system continuously adjusts the stereo projection to the current position of the viewer.

\section{REVIEW OF RELATED WORKS}

Simulations play a major role in education not only because they provide realistic models with which students can interact to acquire real world experiences, but also because they constitute safe environments in which students can repeat processes without any risk in order to perceive easier concepts and theories. VR is widely recognized as a significant technological advance that can facilitate learning process through the development of highly realistic 3D simulations supporting immersive and interactive features [27]. Simulated environments have opened new realms in teaching and learning and have found their way in all areas of human endeavors. VR technology has offered strong benefits in science and education. VR technology has not only facilitated constructivist and socio-constructivist learning activities but also supported different types of learners such as those who are visually oriented and disabled [28].

Sampaio and Henriques [29] demonstrated how the technology of VR can be used in the elaboration of teaching material of educational interest in the area of construction processes. They generated models that represented building in two standard situations. Students can interact with the virtual models in such a way that they can set in motion the construction sequence demanded by actual construction work, observe the methodology applied, analyze in detail every component of the work and the equipment needed to support the construction process and observe how the different pieces of a construction element mesh with each other and become incorporated into the model. Their models were used in disciplines involving construction in courses in Civil Engineering and Architecture administered by the Higher Technical Institute of the University of Lisbon.
Georgiou, Dimitropoulos and Manitsaris [27] presented a novel Web-based virtual learning environment for the simulation of volumetric analysis experiments. Their work took advantage of advances on Web and VR technologies to reproduce conditions of a real learning process in a chemical laboratory and enhance learning through a real-time interactive simulation of volumetric analysis experiments. The virtual laboratory presented in their paper was a cost-effective solution for both schools and universities without appropriate infrastructure and a valuable tool for distance learning and life-long education in chemistry.

Zhang [30] described a simulated environment called Second Life. It is a Web-based multi-user 3D virtual environment developed by Linden Lab, a San Francisco-based company. Second Life is one of the most popular virtual reality tools, attracting educators from all over the world. It offers a variety of opportunities for interaction, sense of community, and users' self-building capabilities. Statistics showed that there are over 100 educational institutes that had established their virtual campus in Second Life and are actively working in the virtual world [31].

Bell [32] proposed the need to introduce VR into engineering curriculum and in 1998, Bell and Fogler [33] developed Vicher (Virtual Chemical Reactors) at the University of Michigan to teach students catalyst decay, nonisothermal effects in kinetics, reactor design and chemical plant safety since they believe that humans retain up to $90 \%$ of what they learn through active participation [28]. Kim et al [34] developed a computer-based virtual reality simulation that helps students to learn physics concepts at the Kongju National University in Korea. This virtual laboratory has helped students' gain laboratory experience and thus improved students' performance [34]. In training and simulation, battlefield simulations have been developed using real data from Desert Storm [35]. US Navy uses flight simulators to help train pilots for general navigation as well as special assignments. US military uses VR simulations to treat phobia in war veterans.

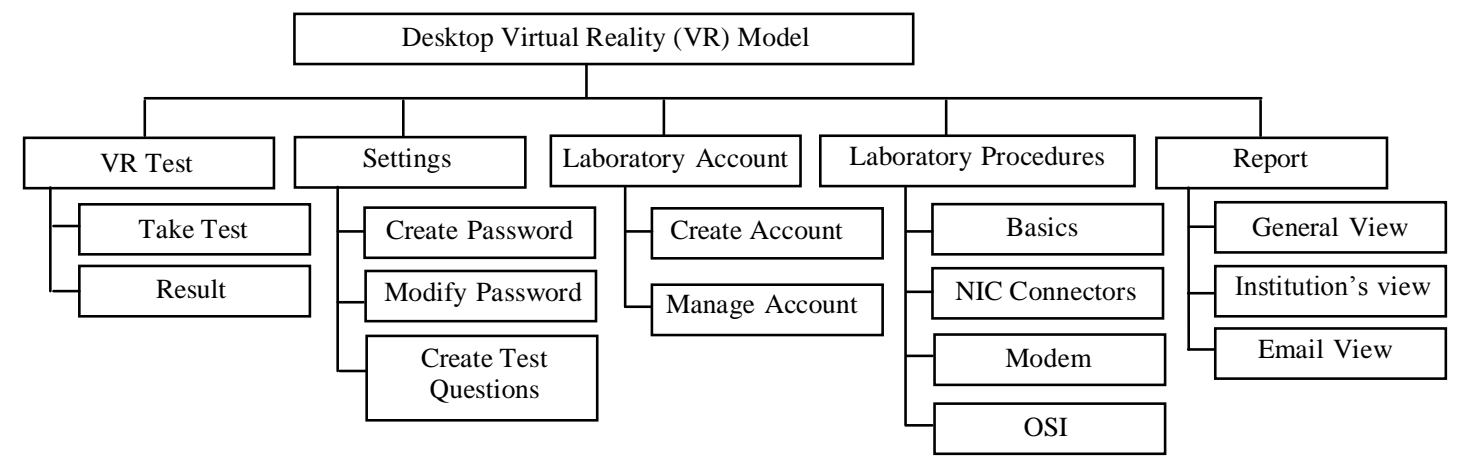

Fig. 1. The High Level Model of the Desktop Virtual Reality System

\section{MATERIALs And MeHOdS}

We adopted a hybrid methodology derived from the combination of the Structured System Analysis and Design Methodology (SSADM), Object Oriented Analysis and Design Methodology (OOADM) and the prototyping methodology.
Using this methodology, we developed and implemented a desktop virtual reality model. The investigative phase of the SSADM was deployed as the paradigm for systematic study in order to obtain information on the current trends in the research area of simulated environments. The information obtained necessitated the definition of a high-level model 
(HLM) for a simulated environment (Fig. 1). Using this HLM, a simulated desktop VR model was implemented. The simulated environment demonstrated Open System Interconnection (OSI) model and network devices (modem and network interface card). Macromedia Flash and Java were used to create the various objects in the simulated environment. Fig. 2 is the user interface of the model. It was designed to be user friendly. The interfaces were required to access information in the database and objects in the virtual world. Microsoft VB.NET and Java were used to implement the graphical user interface (GUI). The GUI was used for interactive querying, data capture, information display, and viewing of objects in the virtual world.

The desktop Virtual Reality Model was used in a class selected that offers fundamentals of networking in the Department of Computer Science at the Anambra State University to assess the impact of constructivism and socioconstructivism on the students. The selected class was divided into three groups. The subject of the assessment was the RJ45 network interface card (NIC) and connector for connecting computers in a single segment. The students were supposed to learn how an RJ45 NIC is identified and installed in a computer system; how to make an RJ45 connector and fitted to the NIC. Each group consisted of two classes of around 25. After presenting these, the students' knowledge improvements were tested and the students' attitudes about the simulated environment were surveyed using a questionnaire and the testing system in the simulated environment. The test consists of 20 numbers of multiple choice items on the subject. The different groups were tested about general knowledge on networking before the simulated environment was used on them.

The first group called "the instructivist group (IG)" did not use the simulated environment at all. In the second group, the simulated environment was used in the class only by a teacher as a supplement to lecture. This group was called "the constructivist group (CG)". The third group called "the socioconstructivist group (SG)" used the simulated environment in the PC room where the students were actively engaged by themselves without any lecture. They had only the study guide papers and were expected to learn by themselves and interact with one another to share their experiences.

\section{Results And Discussions}

The result of the simulated environment is presented in Fig. 2 to Fig. 8 while the impact of this simulated environment on students is presented in Fig. 9 to Fig.10 and Tables 1 to 2.

\section{A. The Simulated Environment}

VR is a powerful tool for education since people comprehend images much faster than they grasp lines of text or columns of numbers. Participation is critical to learning and VR offers multisensory immersive environments that engage students and allow them visualize information.

User Interface:The graphical user interface (GUI) is shown in Fig. 2. The interfaces are required to access information in the database and objects in the virtual world. Microsoft Visualbasic.NET was used to implement the GUI. The GUI was used for interactive querying, data capture, information display, and viewing of objects in the virtual world.

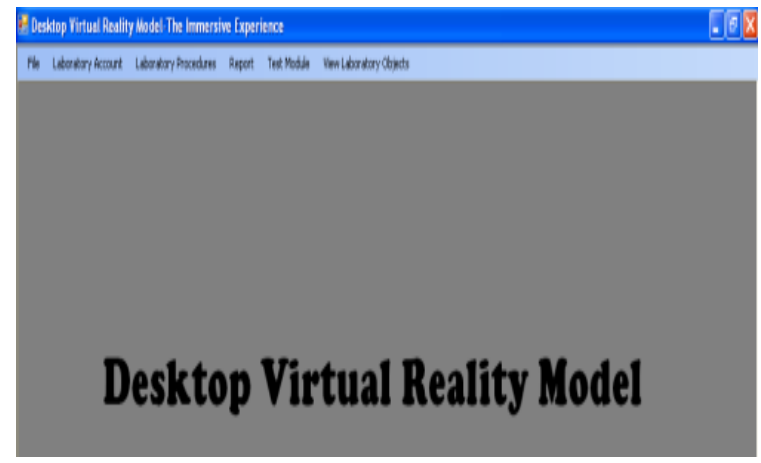

Fig. 2. GUI of the Desktop Virtual Reality System

a) Login Interface: Fig. 3 shows a screen shot of the login user interface. A user who has created an account in the environment uses the login interface to gain access to the simulated environment.

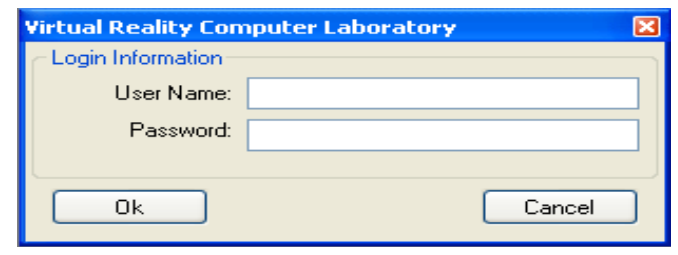

Fig. 3. Login user interface

b) Creatre Account: Fig. 4a and Fig. 4b show screen shots of create account. A new user provides information which is stored in the database. This information is needed so as to monitor users as regards the use of the model and subsequently in taking tests. A new user is first prompted to key in his/her email address and registration number using Fig. 4b. The database is searched to see if these exist. This is so to avoid duplication of record. If such exists, the user is denied registration thus account is not created for such user, else the user is prompted using Fig. 4a to provide other details.

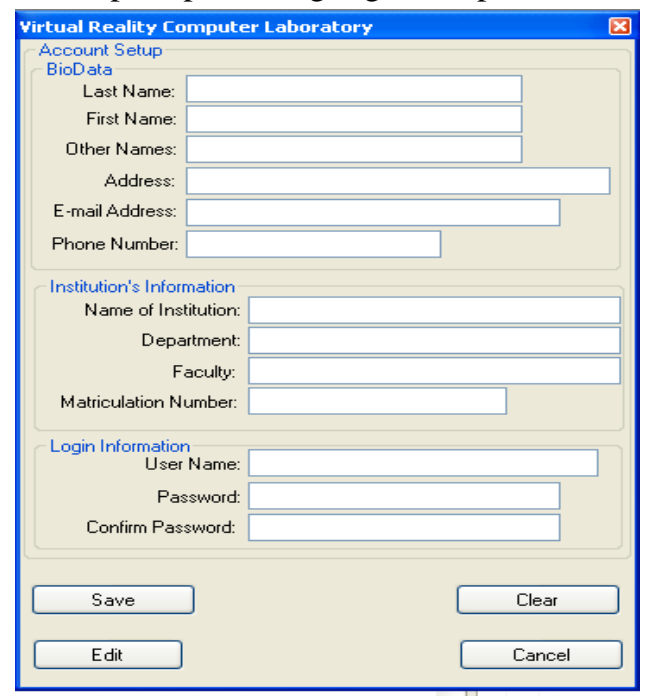

Fig. 4. a: Create account graphical user interface 


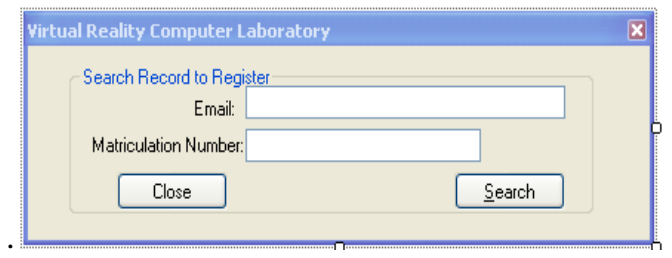

Fig. 4. b:Search database interface

c) Record View Functionality: Fig. 5 shows a screen shot of the view records user interface. This interface is connected to the database using a data source VRLDbase.Dataset.xsd. The field names were chosen to be as close to the real field names to avoid a situation where users become confused as to what each field represents. For identification of any record of choice once it is clicked, it will be highlighted. The application (model) successfully allowed the use of the user interface to present an integrated view of the database information in a transparent manner. The different fields not needed are filtered out leaving only the necessary fields needed.

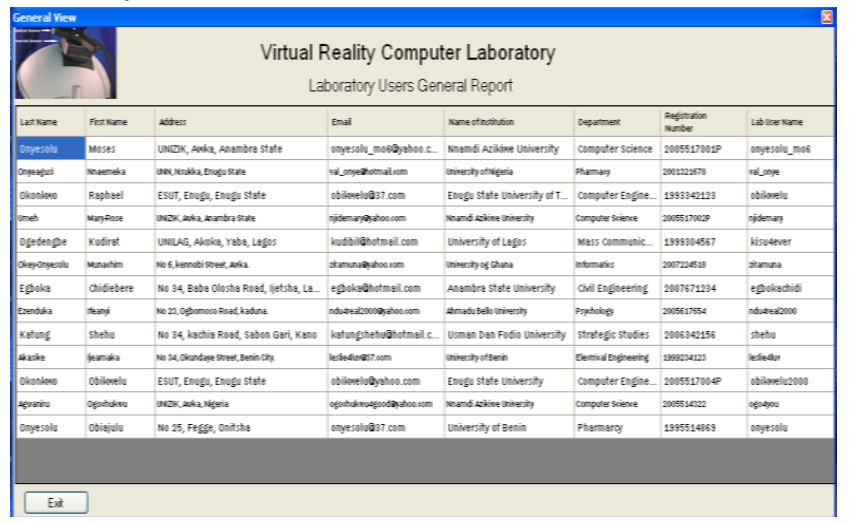

Fig. 5. Record View User Interface

d) Query Record Functionality: Once the model was executed and loaded, from the laboratory account menu, the database can be queried either if a new account is being created or an existing account is to be managed by editing one or more fields not desirable. The screen shots in Fig. $4 \mathrm{a}$ and Fig. 6 are one out of two possible ways to query a record in the database. In Fig. 4a, the query criteria are email and registration number, while in Fig. 6, the query criterion is email. The application was successfully used through the user interface to select condition used to query the records in the database.

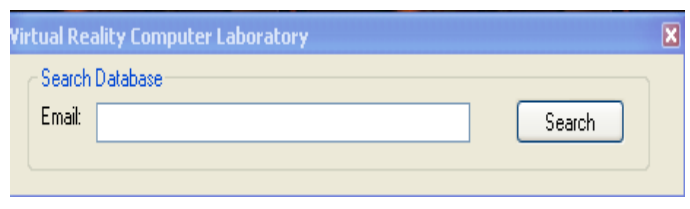

Fig. 6. Query Records User Interface

Laboratory Procedure Functionality:The two laboratory procedures presented were modem - a networking device, and OSI - a networking concept. These two procedures were presented in the form of movies accompanied by a voice output to describe the concept or the device. The movie can be paused, played, and stopped. It can be made to be viewed in full screen when desired. These objects can be manipulated (turned in 3D) to study its essential parts. The screen shots are presented in Fig.7 and Fig. 8. The laboratory procedures demonstrated clearly showed how objects in the virtual world interact, and how these objects are used. The OSI model concept demonstrated in graphical forms what happens to data travel as it originates from the application layer, travels through the layers to the physical layer and vice versa. Because these objects were presented in $3 \mathrm{D}$, comprehension of the concept and the working of the devices were made easy to a learner or user. At the end of a laboratory procedure, a user may want to take a test to determine how far he/she has grasped the concept learnt or the device studied. This is done by taking a test by selecting the test option on the menu. The test provided series of multiple choice questions and each question has four options to choose from. A user can stop the test anytime desired without completing the test. At the end of the test, the test takers name and score obtained are store stored in a database. These can be accessed later if desired, or if the user wished to continue with the test.

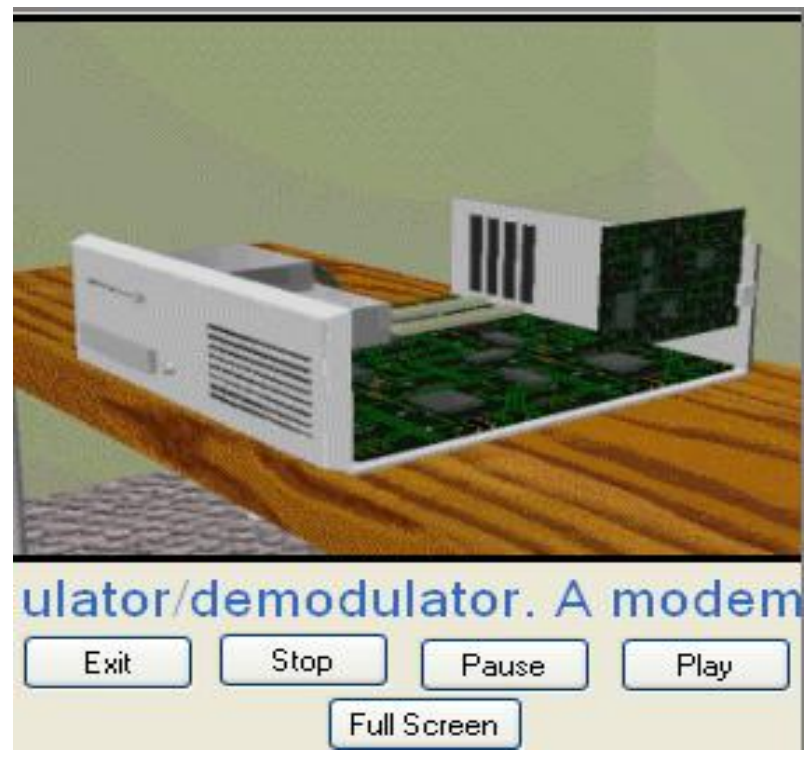

Fig. 7. Connecting modem laboratory procedure

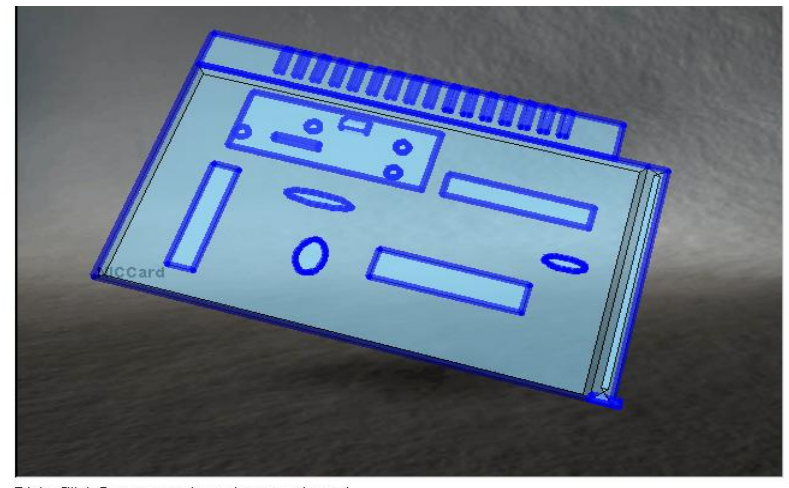

Right Click Image to activate the control panel $\underset{\text { Application Menu }}{\text { Back to... }}$

Fig. 8. Viewing and manipulating an object (modem) procedure 


\section{B. The Impact of the Environment on Students}

TABLE I. Performance Of The Different Group Before The Test

\begin{tabular}{|l|c|c|c|}
\hline \multicolumn{2}{|l|}{ Academic Performance } \\
\hline Group & IG & CG & SG \\
\hline Highest Score & 18 & 18 & 17 \\
\hline Lowest Score & 10 & 08 & 09 \\
\hline Range of Score & \multicolumn{3}{|l|}{} \\
\hline $01-04$ & Nil & Nil & Nil \\
\hline $05-08$ & Nil & 04 & 16 \\
\hline $09-12$ & 12 & 14 & 05 \\
\hline $13-16$ & 08 & 04 & 04 \\
\hline $17-20$ & 05 & 03 & \\
\hline
\end{tabular}

Table I and Fig. 9 show the academic performance of each group before they were exposed to the simulation program and taught the network components. The IG group's performance was slightly superior to other groups. While the highest score in this group was 18, 5 students scored between 17-20 marks. In contrast to CG group and SG group, 3 students and 4 students scored in that range.

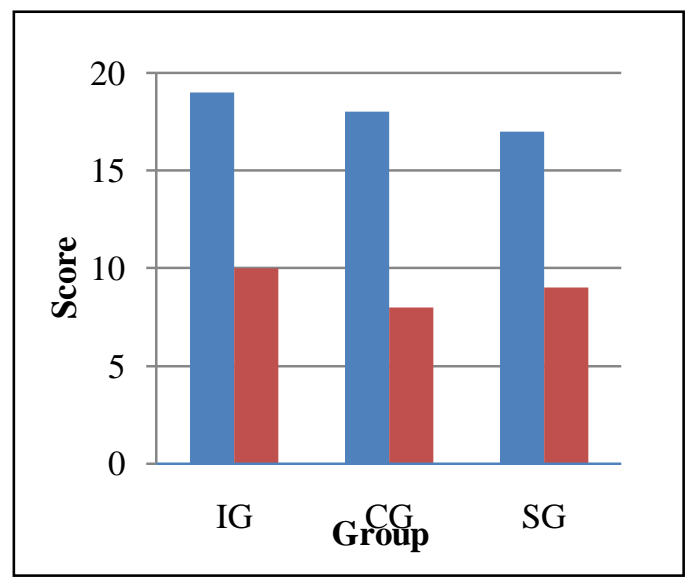

Fig. 9. The academic performance of groups before the test

Table II and Fig. 10 show the academic performance of each group after they were exposed to the simulation program and taught the network components. The SG group's performance was superior to other groups. While the highest score in this group was 19, 9 students scored between 17-20 marks.

In contrast to CG group and SG group, no student scored within that range. The SG group's performance was superior to other groups because it has been demonstrated by [28] that human beings retain up to $90 \%$ of what they learn through active participation.
TABLE II. PERformance Of THE DifFerent Group AFter The Test

\begin{tabular}{|l|c|c|c|}
\hline \multicolumn{4}{|l|}{ Academic Performance } \\
\hline Group & IG & CG & SG \\
\hline Highest Score & 13 & 16 & 19 \\
\hline Lowest Score & 08 & 10 & 14 \\
\hline Range of Score & \multicolumn{3}{l|}{} \\
\hline $01-04$ & Nil & Nil & Nil \\
\hline $05-08$ & 06 & Nil & Nil \\
\hline $09-12$ & 12 & 13 & Nil \\
\hline $13-16$ & 07 & 12 & 16 \\
\hline $17-20$ & Nil & Nil & 09 \\
\hline
\end{tabular}

This facilitated constructivist and socio-constructivist learning. Therefore simulated environments provided the tools with which the students used, visualized and manipulated objects; this made it easier for them to understand how the objects work. It offered tools for increased student participation and a learning experience that they found interesting, this gave them the motivation to learn, interact and shared their experiences with one another.

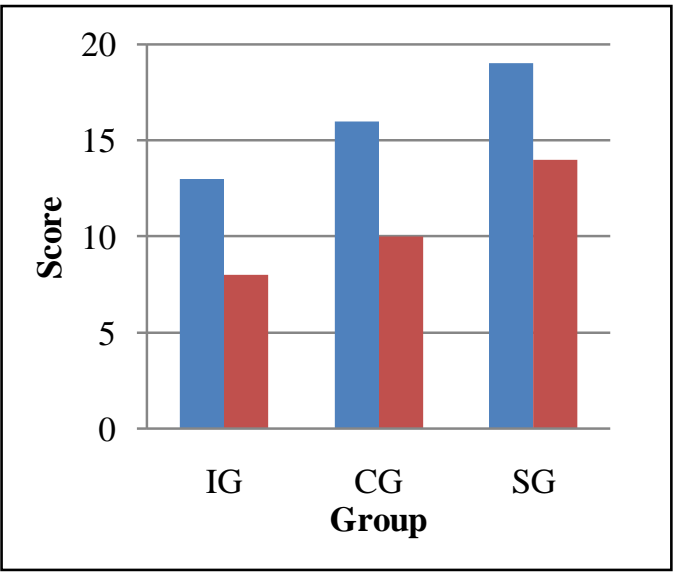

Fig. 10. The academic performance of groups after the test

\section{CONCLUSION}

Researchers in the field of learning theory and VR have generally agreed that VR technology is exciting and provides a unique and effective way for students to learn when it is appropriately designed and applied, and that VR projects are highly motivating to learners [36]. From various researches, several specific situations have emerged in which VR has strong benefits or advantages (as shown in this work). For example, VR has great value in situations where exploration of environments or interactions with objects or people is impossible or inconvenient, or where an environment can only exist in computer-generated form. 
VR is also valuable when the experience of actually creating a simulated environment is important to learning. Creating their own virtual worlds has been shown to enable some students to master content and to project their understanding of what they have learned. One of the beneficial uses of VR occurs when visualization, manipulation, and interaction with information that is critical for its understanding. This is socio-constructivist approach of VR to learning. It is because of VR's capacity for allowing learners to display and interact with information and environment that some believed is its greatest advantage.

Finally, VR is a very valuable instructional and practice alternative when the real thing is hazardous to learners, instructors, equipment, or the environment. This advantage of the technology has been cited by developers and researchers from such diverse fields as firefighting, anti-terrorism training, nuclear decommissioning, crane driving and safety, aircraft inspection and maintenance, automotive spray painting and pedestrian safety for children [36].

In the fields of education, technology has created a paradigm shift. Technology has created new ways of teaching and learning. VR is a new technology that has provided creative ways in which students learn opportunities to guide classroom instruction to meet all learners.

The use of VR techniques in the development of educational applications brings new perspectives to the teaching of subjects. VR is potentially a tool for experiential learning. VR has opened new realms in the teaching, learning, and practice of medicine, physical sciences and engineering among others. Virtual reality learning environments (VLEs) provide students with the opportunity to achieve learning goals.

VLE-based applications have emerged in mainstream education in schools and universities as successful tools to replace traditional teaching methods (instructivist approach). VR learning environments have been discovered to have greater pedagogical effectiveness on learners because it encompasses instructivism, constructivism and culminated in socio-constructivism.

\section{REFERENCES}

[1] M.O. Onyesolu, "Extent of computer education acquisition in Nigeria: Conflict between policy pronouncements and policy implementations," Journal of Applied Sciences, vol. 12, no. 1. pp. 8212-8221, March 2009.

[2] A. Esu, and A. Junaid, "Educational development: Traditional and contemporary." Retrieved February 30, $2013 . \quad$ Source: http://www.onlinenigeria.com/education/

[3] M.O Onyesolu, O.F Oladipo, and I.M. Ezeani, "Simulating desktop virtual reality for higher education," International Journal of Ubiquitous Sciences, vol. 1, issue 1, pp. 1-6. June, 2012.

[4] O. Olufemi, "Pedagogical approaches and technical subject teaching through internet media," The Electronic Journal of e-Learning, vol. 6, no.1, pp.53-66, 2008.

[5] R. Ginberg and V. McCornick, "Computer use in effective schools," Journal of Staff Development, vol. 19 no. 1, pp. 22-5, 1998.

[6] E. Hyslop-Margison, "Technology, human agency and Dewey's constructionism: Opening democratic spaces in virtual classrooms," Austrarian Journal of Educational Technology. vol. 20, no. 2, pp. 137148, 2004.
[7] M.O. Onyesolu, "Virtual Reality: An emerging computer technology of the $21^{\text {st }}$ century," International Journal of Electrical and Telecommunication System Research. vol.1, no. 1, pp. 36-40, 2006.

[8] D.P. Diaz and K.F. Bonteball, Pedagogy-based Technology Training. Amsterdam: IOS Press, 2000.

[9] M. Matthews, "Discontent with constructivism," Studies in Science Education, vol. 24, pp. 165-172, 1994.

[10] G. Erikson, Research programmes and the student science learning literature. In R. Millar, J. Leach, J. Osborne (Eds.): Improving Science education: The contributions of research. Buckingham: open University Press, 2000.

[11] K.S. Taber, "Beyond Constructivism: The progressive research programme into learning science," Studies in Science and Education, vol. 42, pp. 125-184, 2006.

[12] S. Sjoberg, In E. Baker, E., B. McGaw, and P. Peterson (Eds.), International Encyclopeadia of Education, 3rd Ed., Oxford: Elsevier, 2007.

[13] R. Driver and J. Easly, "Pupils and Paradigms: A review of literature related to concept development in adolescent science students," Studies in Science Education, vol. 5, pp. 61-84, 1978.

[14] H. Nikitina, "Addressing pedagogical dilemmas in a constructivist language," Journal of the Scholarship of Teaching and Learning. vol. 10, no. 2, pp. 90-106, 2010.

[15] H. Huang, "Towards constructivism for adult learners in online learning environments," British Journal of educational Technology, vol. 33, no. 1, pp. 27-37, 2002.

[16] M.S. Knowles, E.F. Holton and R.A. Swanson, The Adult Learner: The Definitive Classic in Adult Education and Human Resource Development. $7^{\text {th }}$ Edition, London: Elsevier, 2011.

[17] M. McMahon,Social constructivism and thw world wide web-A paradigm for learning. Proceedings ASCILITE97 Conference, Curtin University, Perth, 1997. Retrieved March 13, 2013. Source http://www.ascilite.org.au/conferences/perth97/papers/Mcmahon/Mcma hon.html

[18] A. Kukla, Social Constructivism and the Philosophy of Science, New York: Routledge, 2000.

[19] R.S. Prawat and R.E. Floden, "Philosophical perspectives on constructivist views of learning," Educational Psychologist, vol. 29, no. 1, pp. 37-48, 1994.

[20] B. Rogolf, Apprenticeship in thinking: Cognitive development in social context. New York, NY: Oxford University Press, 1990.

[21] M.E. Gredler, Learning and instruction: Theory into practice, ( $3^{\text {rd }}$ Ed.). Upper Saddle River, New Jersey: Prentice-Hall, 1997.

[22] C. Macpherson and M. Keppell, "Virtual reality: What is the state of play in education?" Australian Journal of Educational Technology. vol. 14, no. 1, pp. 60-74, 1998.

[23] M.O. Onyesolu, "Modeling and Simulation of Desktop Virtual Reality," Unpublished Doctoral Dissertation, Department of Computer Science, Nnamdi Azikiwe University, Awka, Nigeria, 2011.

[24] M. Slater, M. Usoh and A. Steed, "Depth of presence in virtual environments," Teleoperators and Virtual Environments, vol. 3, no. 2, pp. 130-144, 1994.

[25] Wikipedia the free encyclopedia (2013). Virtual Reality. Retrieved March 13, 2013. Source: http://en.wikipedia.org/wiki/Virtual_reality

[26] M.O. Onyesolu and F.U.Eze, Understanding Virtual Reality Technology: Advances and Applications, in M. Schmidt, (Ed.) Advances in Computer Science and Engineering, Rijeka, Croatia: InTech Open Access Publishers, 2011.

[27] J. Georgiou, K. Dimitropoulos and A. Manitsaris, "Virtual reality laboratory for distance education in chemistry," International Journal of Social Sciences, vol. 2, no. 1, pp. 34-41, 2007.

[28] D. Edgar, Audio-Visual Methods in Teaching. 3rd ed. London: Holt, Rinehart, and Winston, 1969.

[29] A.Z. Sampaio and P.G. Henriques, "Virtual Reality technology applied in Civil Engineering education," Current Developments in TechnologyAssisted Education, pp. 1351-1355, 2006. 
[30] J. Zhang, "Second life: Hype or reality?" Higher Education in the Virtual World, 2007. [Online]. Available: http://deoracle.org/onlinepedagogy/emerging-technologies/second-life.html

[31] K. Joly, A second life for higher education, 2007. Retrieved March 15, 2013. http://www.universitybusiness.com/viewarticle.aspx?articleid=797

[32] J.T. Bell, Introducing virtual reality into the engineering curriculum, Proc. of University Programs in Computer Aided Engineering and Design Manufacturing, Charlottesville, VA., 1996. [Online], Available: http://www.vrupl.evl.uic.edu/vrichel/.

[33] J.T Bell and H.S Fogler, H.S. Virtual Reality in the Chemical Engineering Classroom, Proc. of American Society for Engineering Education Annual Conference, Seattle, WA., 1998.

[34] J. Kim, S. Park, K. Yuk, H. Lee and H. Lee, Virtual reality simulations in physics education. Interactive Multimedia Electronic Journal of Computer-Enhanced Learning (IMEJ of CEL), 2000. [Online]. Available: http://imej.wfu.edu/articles/2001/2/02/index.asp

[35] B.Schmitz, "Virtual reality: On the brink of greatness," Computer-Aided Engineering, pp. 26-32, 1993.

[36] L.J. Ausburn and F.B. Ausburn, "Desktop virtual reality: A powerful new technology for teaching and research in indutrial teacher education," Journal of Industrial Teacher Education, vol. 41, no. 4, 2004. [Online]. http://scholar.lib.vt.edu/ejournals/JITE/v41n4/ausburn.html

\section{AUTHORS PROFILE}

Moses Okechukwu Onyesolu has a Ph.D (Virtual Reality), M.Sc. (Internet Computing), B.Sc. (Computer Science) from Nnamdi Azikiwe University, Nigeria where he works as a lecturer and researcher. His research interests are mainly in computer modeling and simulation, e-learning/virtual reality technologies, queueing system/theory and its applications. He has published widely in those areas. He is a member of the following learned societies: Nigerian Computer Society (NCS), Computer Professionals (Registration Council of Nigeria) (CPN), and International Association of Engineers (IAENG), International Association of Computer Science and Information Technology (IACSIT) and European Association for Programming Languages and Systems (EAPLS)

Victor Chekume Nwasor is with the Department of Educational Foundations, Nnamdi Azikiwe University, Awka, Anambra State. He is a member of the following learned societies: Nigerian Council for Educational Psychologists and Nigerian Society for Educational Psychology.

Obiajulu Ekene Ositanwosu has B.Sc. (Computer Science) from Nnamndi Azikiwe University, Awka, Anambra State where he works as a teaching assistant. He is a graduate student in the Department of Computer Science, Nnamdi Azikiwe University. His research interests are in the area of elearning, biometrics/securities and computer modeling and simulation.

Obinna Nnamdi Iwegbuna has B.Sc. (Computer Science) from Nnamndi Azikiwe University, Awka, Anambra State where he works as a technologist. $\mathrm{He}$ is a graduate student in the Department of Computer Science, Nnamdi Azikiwe University. His research interests are in the area of e-learning and biometrics/securities. 